Received: 2015.08 .15

Accepted: 2015.10.27

Published: 2016.04 .22

\title{
Diagnostic Accuracy of Real-Time Shear Wave Elastography for Staging of Liver Fibrosis: A Meta-Analysis
}

Authors' Contribution: Study Design A Data Collection B Statistical Analysis C Data Interpretation D Manuscript Preparation E Literature Search F Funds Collection G
ABCDEF 1 Changtian Li*

ABCDEF 2 Changsheng Zhang*

AD 1 Junlai Li

BCDF 1 Huiping Huo

BCDF 1 Danfei Song
1.Department of Ultrasound, The Southern Building, Chinese PLA General Hospital, Beijing, P.R. China

2 Anesthesia and Operation Center, Chinese PLA General Hospital, Beijing, P.R. China
Corresponding Author: Source of support:
* These authors contributed equally to this work Junlai Li, e-mail: li_jl@yeah.net

Departmental sources

Background: The present meta-analysis, based on previous studies, was aimed to evaluate the test accuracy of real-time shear wave elastography (SWE) for the staging of liver fibrosis.

Material/Methods:

A systematic search on MEDLINE, PubMed, Embase, and Google Scholar databases was conducted, and data on SWE tests and liver fibrosis staging were collected. For each cut-off stage of fibrosis ( $F \geq 2, F \geq 3$, and $F \geq 4$ ), pooled results of sensitivity, specificity, and area under summary receiver operating characteristic (SROC) curve were analyzed. The study heterogeneity was evaluated by $\chi^{2}$ and $I^{2}$ tests. $I^{2}>50 \%$ or $P \leq 0.05$ indicates there was heterogeneity, and then a random-effects model was applied. Otherwise, the fixed-effects model was used. The publication bias was evaluated using Deeks funnel plots asymmetry test and Fagan plot analysis was performed.

Results: $\quad$ Finally, 934 patients from 8 published studies were included in the analysis. The pooled sensitivity and specificity of SWE for $\mathrm{F} \geq 2$ were $85.0 \%(95 \% \mathrm{Cl}, 82-88 \%)$ and $81 \%(95 \% \mathrm{Cl}, 71-88 \%)$, respectively. The area under the SROC curve with $95 \% \mathrm{Cl}$ was presented as 0.88 (95\% Cl, 85-91\%). The pooled sensitivity and specificity of SWE for $\mathrm{F} \geq 3$ were $90.0 \%(95 \% \mathrm{Cl}, 83.0-95.0 \%)$ and $81.0 \%$ (95\% Cl, 75.0-86.0\%), respectively, corresponding to an area of SROC of $0.94(95 \% \mathrm{Cl}, 92-96 \%)$. The pooled sensitivity and specificity of SWE for $\mathrm{P} \geq 4$ were $87.0 \%$ (95\% Cl, 80.0-92.0\%) and $88.0 \%(95 \% \mathrm{Cl}, 80.0-93.0 \%)$, respectively, corresponding to an area of SROC of 0.92 (95\% Cl, 89-94\%).

Conclusions: The overall accuracy of SWE is high and clinically useful for the staging of liver fibrosis. Compared to the results of meta-analyses on other tests, such as RTE, TE, and ARFI, the performance of SWE is nearly identical in accuracy for the evaluation of cirrhosis. For the evaluation of significant liver fibrosis ( $\mathrm{F} \geq 2)$, the overall accuracy of SWE seems to be similar to ARFI, but more accurate than RTE and TE.

MeSH Keywords:

Abbreviations:

Full-text PDF:

\section{Diagnosis • Elasticity Imaging Techniques • Fibrosis • Meta-Analysis}

SWE - shear wave elastography; SROC - summary receiver operating characteristic; CLDs - chronic liver diseases; HCC - hepatocellular carcinoma; LB - liver biopsy; RTE - real-time tissue elastography; TE - transient elastography; ARFI - acoustic radiation force impulse imaging; TP - true positive; FP - false positive; FN - false negative; TN - true negative; NPV - negative predictive value; PPV - positive predictive value; QUADAS - quality assessment for studies of diagnostic accuracy; Cls - confidence intervals; HCV - hepatitis C virus; HBV - hepatitis B virus; ALT - alanine transaminase

http://www.medscimonit.com/abstract/index/idArt/895662

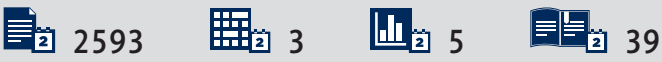




\section{Background}

In patients suffering from chronic liver diseases (CLDs), the necrosis of hepatocytes and the progression of inflammatory reaction cause liver fibrosis [1]. Without timely and appropriate intervention, the liver fibrosis gradually progresses into cirrhosis, hepatocellular carcinoma (HCC), and, ultimately, liver failure [2]. The staging, i.e., the classification and identification of stages or degree of liver fibrosis, is of major clinical concern, because it is the strongest prognostic indicator and crucial for the optimization of treatment strategies [3].

Currently, liver biopsy (LB) is considered as the criterion standard to evaluate the degree of liver fibrosis [4,5]. However, liver biopsy is an invasive method possibly causing pain, hemorrhage, and even mortality. Moreover, liver biopsy is susceptible to inter/ intra-observer variability, sampling error, and other limits [6-8]. In the recent years, the advances in imaging technology have enabled quantitative and noninvasive measurements of liver stiffness with various ultrasound-based elastographic methods, including Real-time Tissue Elastography (RTE), Transient Elastography (TE) (Fibroscan; Echosense, Paris, France), Acoustic Radiation Force Impulse Imaging (ARFI; Siemens, Erlangen, Germany), and Real-time Shear Wave Elastography (SWE) (Aixplorer; Supersonic Imagine, Aix-en-Provence, France) [9-13]. Among these methods, SWE is a new real-time technique using measurements of acoustically generated tissue shear wave propagation velocity to derive the estimates of liver stiffness. SWE has the advantages of providing anatomic B-mode US images and elastographic color maps according to the degree of stiffness simultaneously, which offers the potential of enhanced accuracy in the assessment of liver stiffness $[14,15]$.

RTE, TE, and ARFI have been evaluated in several meta-analyses for their roles in staging liver fibrosis, and were shown to have clinically satisfactory high accuracy for the diagnosis of cirrhosis but intermediate accuracy for differentiating between mild and moderate liver fibrosis [16-18]. Although an increasing number of studies have evaluated the utility of SWE in assessing the degree of liver fibrosis, wide ranges of sensitivity and specificity were reported [12,14,15,19-28]. A systematic approach to this topic integrating the SWE data from independent studies may provide a better assessment of the utility of SWE in liver fibrosis staging. Therefore, we performed a meta-analysis to assess the overall performance of SWE in the diagnosis of liver fibrosis.

\section{Material and Methods}

\section{Search strategy}

Relevant published studies present in the databases of MEDLINE, PubMed, Embase, and Google Scholar were searched using the following terms: (elastography OR shear wave elastography) AND (liver OR hepatic) AND (diagnosis OR diagnostic test). For each relevant published study thus identified, the references cited in the study were further scrutinized to obtain more related studies. Our analysis was performed in accordance with the PRISMA statement.

\section{Study inclusion}

To be included, the articles had to meet the following criteria. First, the articles assessed the effects of SWE in diagnosis of liver fibrosis stages with quantitative determination. Second, the diagnosis of liver fibrosis was confirmed using the liver biopsy as the criterion standard and the fibrosis stages were scored according to METAVIR or comparable staging systems. Third, the studies provided available data on true positive (TP), false positive (FP), false negative (FN), and true negative (TN) or reported sufficient data (sensitivity, specificity, negative predictive value [NPV] and positive predictive value [PPV]) to derive these parameters. Fourth, every study enrolled at least 30 patients. Fifth, if 2 or more publications came from the same primary study, the publication with larger the sample size was included.

The methodological quality of each article was evaluated by the Quality Assessment for Studies of Diagnostic Accuracy (QUADAS) tool (Table 1).

\section{Data extraction}

Two investigators independently extracted the following data from each article using standardized forms: 1) name of first author; 2) year of publication; 3) country; 4) number of patients; 5) sex distribution; 6) mean age, 7) diagnosis of liver diseases; 8) SWE parameter; 9) measurement location; and 10) cutoff stage of fibrosis. Disagreements were resolved by discussion between the 2 investigators.

\section{Statistical analysis}

According to the METAVIR scoring system, the hepatic fibrosis could be staged into 5 groups (FO, no fibrosis; F1, portal fibrosis without septa; F2, portal fibrosis and few septa, but intact architecture; F3, numerous septa, architectural distortion, but no obvious cirrhosis; and F4, cirrhosis). Our assessments of the diagnostic accuracy were made for the discrimination of F0 versus F1-4, F0/ 1 versus F2-4, F0-2 versus F3/4, and $\mathrm{FO}-3$ versus $\mathrm{F} 4$. In this study, these discriminations were also described as $F \geq 1, F \geq 2, F \geq 3$, and $F \geq 4$, respectively. Based on this, the $2 \times 2$ contingency tables including TP, FP, TN, and FN results were established. The pooled sensitivity and specificity with corresponding $95 \%$ confidence intervals (Cls) were used to analyze the degree of accuracy of SWE in identifying the stages of liver fibrosis. The summary receiver operating characteristic (SROC) curve also was used to present the results. 
Table 1. Quality assessment of included sutdies.

\begin{tabular}{|c|c|c|c|c|c|c|c|c|c|c|c|c|c|c|c|}
\hline & Q1 & Q2 & Q3 & Q4 & Q5 & Q6 & Q7 & Q8 & Q9 & Q10 & Q11 & Q12 & Q13 & Q14 & \\
\hline $\begin{array}{l}\text { Author, } \\
\text { year }\end{array}$ & 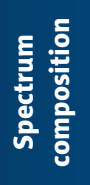 & 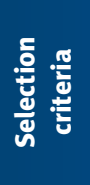 & 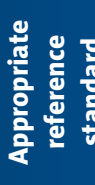 & 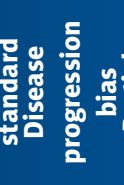 & 蛋 & 焉 & 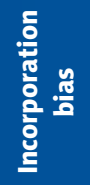 & 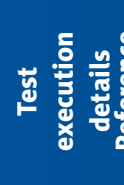 & 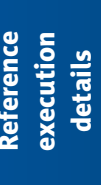 & 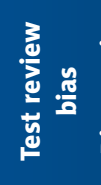 & 号 & $\frac{\sqrt[3]{3}}{\frac{3}{3}} \frac{4}{3}$ & 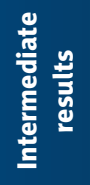 & 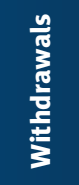 & 。ั \\
\hline $\begin{array}{l}\text { Beland } \\
\text { et al., } \\
2014\end{array}$ & Yes & Yes & Yes & Yes & Yes & Yes & Yes & Yes & Yes & Yes & Yes & Yes & Yes & Yes & 14 \\
\hline $\begin{array}{l}\text { Ferraioli } \\
\text { et al., } \\
2012\end{array}$ & Yes & Yes & Yes & Yes & Yes & Yes & Yes & Yes & Yes & Yes & Yes & Yes & Yes & Yes & 14 \\
\hline $\begin{array}{l}\text { Zeng } \\
\text { et al., } \\
2014\end{array}$ & Yes & Yes & Yes & Yes & Yes & Yes & Yes & Yes & Yes & Yes & Yes & Yes & Yes & Yes & 14 \\
\hline $\begin{array}{l}\text { Yoon } \\
\text { et al., } \\
2014\end{array}$ & Yes & Yes & Yes & Unclear & Yes & Yes & Yes & Yes & Yes & Unclear & Yes & Yes & Yes & Yes & 12 \\
\hline $\begin{array}{l}\text { Jeong } \\
\text { et al., } \\
2014\end{array}$ & Yes & Yes & Yes & Unclear & Yes & Yes & Yes & Yes & Yes & Yes & Unclear & - Yes & Yes & Yes & 12 \\
\hline $\begin{array}{l}\text { Samir } \\
\text { et al., } \\
2014\end{array}$ & Yes & Yes & Yes & Yes & Yes & Yes & Yes & Yes & Yes & Yes & Yes & Yes & Yes & Yes & 14 \\
\hline $\begin{array}{l}\text { Zheng } \\
\text { et al., } \\
2015\end{array}$ & Yes & Yes & Yes & Yes & Yes & Yes & Yes & Yes & Yes & Yes & Yes & Yes & Yes & Yes & 14 \\
\hline $\begin{array}{l}\text { Tada } \\
\text { et al., } \\
2015\end{array}$ & Yes & Yes & Yes & Unclear & Yes & Yes & Yes & Yes & Yes & Yes & Yes & Yes & Yes & Yes & 13 \\
\hline
\end{tabular}

$\chi^{2}$ and $I^{2}$ tests were calculated to evaluate the study heterogeneity. $I^{2}>50 \%$ or $P \leq 0.05$ suggests the heterogeneity exists, and a random-effects model was applied in the analysis for the heterogenic data. Otherwise, the fixed-effects model was applied. The publication bias was assessed by Deeks funnel plot asymmetry test. Fagan plot analysis was also performed. Pre-test probabilities of $25 \%, 50 \%$, and $75 \%$ were assumed. The corresponding post-test probabilities were calculated following a "positive" or "negative" result based on the summary sensitivity and specificity of SWE, which showed the relationship among the prior probability specified, the likelihood ratio, and posterior test probability $[18,29]$. The meta-analysis was completed in Stata 12.0 (StataCorp., College Station, TX, USA).

\section{Results}

\section{Study characteristics}

A total of 405 published studies were retrieved using the search strategy described in the methods section. We excluded
350 articles for lack of relevance, based on inspecting the abstracts. Full texts of 55 articles were obtained for further evaluation. Then, 8 articles were selected in the meta-analysis $[14,15,19-22,26,27]$ (Figure 1). The 8 published studies were performed in the United States, Italy, China, Korea, and Japan. There were 934 patients and their ages ranged from 12 to 82 years. Diseases etiology was categorized as hepatitis $C$ virus (HCV), hepatitis B virus (HBV), and others. All the studies used the METAVIR scoring system. The adopted diagnosis parameter was $E$ (Young's modulus) expressed in $\mathrm{kPa}$. The features of the studies are shown in Table 2. It should be mentioned that in the study conducted by Beland et al., the liver stiffness was measured in $\mathrm{kPa}$ on an ultrasound machine and converted to $\mathrm{m} / \mathrm{s}$ by using the conversion formula [22].

\section{Summary estimates of sensitivity and specificity}

Table 3 shows the test results of SWE in identifying the stages of liver fibrosis: area under curve (AUC), cutoff values, sensitivity, and specificity. There was no study discriminating F0 versus F1-4. Therefore, the data for $\mathrm{F} \geq 1$ were not synthesized. 


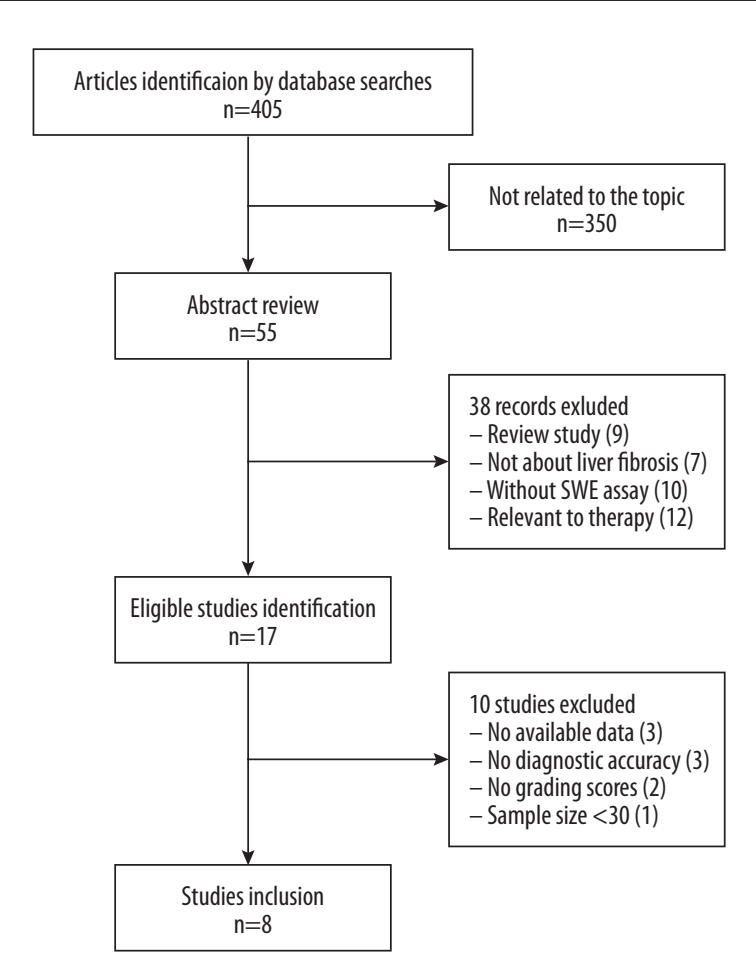

Figure 1. Flow chart for articles selection in the meta-analysis. We obtained 405 articles in the search. After 350 articles were excluded for not being related to the topic, 55 records were used for further evaluation. Finally, 8 articles were included.
The 8 studies all provided quantitative values for discriminating F0/1 versus F2-4. A total of 934 patients were included in the meta-analysis. The cutoff value ranged from $6.65-8.8 \mathrm{kPa}$. The pooled analysis indicated that the overall sensitivity and specificity were $85.0 \%(95 \% \mathrm{Cl}, 82-88 \%)$ and $81 \%(95 \% \mathrm{Cl}, 71-$ $88 \%$ ), respectively (Figure 2). The area under SROC curve with $95 \% \mathrm{Cl}$ was presented as 0.88 (95\% Cl, 0.85-0.91) (Figure 3).

The diagnostic accuracies of SWE for $\mathrm{F} \geq 3$ and $\mathrm{F} \geq 4$ were also evaluated. A total of 533 patients were included to analyze the test results of SWE for $F \geq 3$. The combined outcomes revealed the test sensitivity and specificity at $90.0 \%(95 \% \mathrm{Cl}$, $83.0 \%-95.0 \%)$ and $81.0 \%(95 \% \mathrm{Cl}, 75.0-86.0 \%)$, respectively, for $\mathrm{F} \geq 3$ (Figure 2). The corresponding area of SROC was 0.94 $(95 \% \mathrm{Cl}, 0.92-0.96)$ (Figure 3). A total of 700 patients were included to analyze the test of SWE for the detection of liver cirrhosis $(F \geq 4)$. The test sensitivity and specificity of SWE were $87.0 \%(95 \% \mathrm{Cl}, 80.0-92.0 \%)$ and $88.0 \%(95 \% \mathrm{Cl}, 80.0$ $93.0 \%)$ (Figure 2). The area of SROC was 0.92 (95\% Cl, 0.890.94) (Figure 3).

\section{Study heterogeneity and publication bias}

In the heterogeneity test, the sensitivity of $\mathrm{F} \geq 2 \quad\left(\mathrm{I}^{2}=1.16 \%\right.$, $\mathrm{P}=0.42)$, specificity of $\mathrm{F} \geq 3 \quad\left(\mathrm{I}^{2}=47.32 \%, \mathrm{P}=0.13\right)$ and sensitivity of $\mathrm{F} \geq 4\left(\mathrm{I}^{2}=15.48 \%, \mathrm{P}=0.32\right)$ showed no heterogeneity, while there were heterogeneities for specificity of $F \geq 2 \quad\left(I^{2}=86.43 \%\right.$, $P<0.01)$, sensitivity of $F \geq 3\left(I^{2}=51.32 \%, P=0.10\right)$, and specificity of $F \geq 4\left(I^{2}=78.05 \%, P<0.01\right)$. Therefore, the sensitivity of $F \geq 2$,

Table 2. Characteristics of studies evaluating the performance of SWE for staging of liver fibrosis.

\begin{tabular}{|c|c|c|c|c|c|c|}
\hline Study & Age & $\begin{array}{l}\text { Sample } \\
\text { size }\end{array}$ & Male, $\mathbf{n}$ & $\begin{array}{l}\text { Disease } \\
\text { spectrum }\end{array}$ & $\begin{array}{l}\text { Detection } \\
\text { position }\end{array}$ & $\begin{array}{l}\text { Cut-off stage of } \\
\text { fibrosis }\end{array}$ \\
\hline Beland et al. 2014 (America) [20] & $21-72$ & 50 & 25 & $\mathrm{HCV}$, others & The biopsy site & $F \geq 2$ \\
\hline Ferraioli et al. 2012 (Italy) [17] & $19-76$ & 121 & 87 & $\mathrm{HCV}$ & The right lobe & $F \geq 2, F \geq 3, F \geq 4$ \\
\hline Zeng et al. 2014 (China) [18] & $20-59$ & 206 & 167 & HBV & The right lobe & $F \geq 2, F \geq 3, F \geq 4$ \\
\hline Yoon et al. 2014 (Korea) [19] & $18-75$ & 129 & 87 & $\begin{array}{l}\text { HBV, HCV, } \\
\text { others }\end{array}$ & The right lobe & $\mathrm{F} \geq 2$ \\
\hline Jeong et al. 2014 (Korea) [13] & $12-82$ & 70 & 32 & $\begin{array}{l}\text { HBV, HCV, } \\
\text { others }\end{array}$ & The right lobe & $F \geq 2, F \geq 3, F \geq 4$ \\
\hline Samir et al. 2014 (America) [12] & $18-74$ & 136 & 70 & $\mathrm{HCV}$, others & $\begin{array}{l}\text { The right upper } \\
\text { lobe }\end{array}$ & $F \geq 2, F \geq 3, F \geq 4$ \\
\hline Zheng et al. 2015 (China) [24] & $18-67$ & 167 & 119 & $\begin{array}{l}\text { HBV, HCV, } \\
\text { others }\end{array}$ & The right lobe & $F \geq 2, F \geq 4$ \\
\hline Tada et al. 2015 (Japan) [25] & $24-78$ & 55 & 23 & $\mathrm{HCV}$ & The right lobe & $\mathrm{F} \geq 2$ \\
\hline
\end{tabular}

HCV - hepatitis C virus; HBV - hepatitis B virus. 
Table 3. The test results of SWE in detecting the stages of liver fibrosis.

\begin{tabular}{|c|c|c|c|c|c|c|c|c|c|c|}
\hline \multirow[b]{2}{*}{ Study } & \multirow{2}{*}{$\begin{array}{l}\text { Diagnosis } \\
\text { parameter }\end{array}$} & \multicolumn{3}{|c|}{ Fibrosis $F \geq 2$} & \multicolumn{3}{|c|}{ Fibrosis $F \geq 3$} & \multicolumn{3}{|c|}{ Fibrosis $F \geq 4$} \\
\hline & & Cut-off & $\begin{array}{c}\text { Sensitivity/ } \\
\text { specificity (\%) }\end{array}$ & AUC & Cut-off & $\begin{array}{l}\text { Sensitivity/ } \\
\text { specificity (\%) }\end{array}$ & AUC & Cut-off & $\begin{array}{l}\text { Sensitivity/ } \\
\text { specificity (\%) }\end{array}$ & AUC \\
\hline $\begin{array}{l}\text { Beland } \\
\text { et al. } \\
2014 \text { [20] }\end{array}$ & SWV & $1.87 \mathrm{~m} / \mathrm{s}$ & $75 / 75$ & 0.82 & NA & NA/NA & NA & NA & NA/NA & NA \\
\hline $\begin{array}{l}\text { Ferraioli } \\
\text { et al. } \\
2012 \text { [17] }\end{array}$ & $E$ & $7.1 \mathrm{kPa}$ & $90 / 87.5$ & 0.92 & $8.7 \mathrm{kPa}$ & $97.3 / 95.1$ & 0.98 & $10.4 \mathrm{kPa}$ & $87.5 / 96.8$ & 0.98 \\
\hline $\begin{array}{l}\text { Zeng } \\
\text { et al. } \\
2014 \text { [18] }\end{array}$ & $E$ & $7.2 \mathrm{kPa}$ & $86.36 / 86.96$ & 0.917 & $9.1 \mathrm{kPa}$ & $91.94 / 85.71$ & 0.945 & $11.7 \mathrm{kPa}$ & $91.89 / 89.7$ & 0.945 \\
\hline $\begin{array}{l}\text { Yoon } \\
\text { et al. } \\
2014 \text { [19] }\end{array}$ & $E$ & $6.65 \mathrm{kPa}$ & $78.8 / 75.6$ & 0.852 & NA & NA/NA & NA & NA & NA/NA & NA \\
\hline $\begin{array}{l}\text { Jeong } \\
\text { et al. } \\
2014 \text { [13] }\end{array}$ & E & $8.6 \mathrm{kPa}$ & $78.2 / 93.3$ & 0.915 & $10.46 \mathrm{kPa}$ & $88.6 / 80$ & 0.913 & $14 \mathrm{kPa}$ & $77.3 / 85.4$ & 0.878 \\
\hline $\begin{array}{l}\text { Samir } \\
\text { et al. } \\
2014 \text { [12] }\end{array}$ & E & $7.29 \mathrm{kPa}$ & $91.4 / 52.5$ & 0.77 & $8.9 \mathrm{kPa}$ & $76.5 / 76.5$ & 0.82 & $9.59 \mathrm{kPa}$ & $71.4 / 82.2$ & 0.82 \\
\hline $\begin{array}{l}\text { Zheng } \\
\text { et al. } \\
2015 \text { [24] }\end{array}$ & $E$ & NA & $85.7 / 73.9$ & 0.86 & NA & NA/NA & NA & NA & $91.2 / 79.7$ & 0.93 \\
\hline $\begin{array}{l}\text { Tada } \\
\text { et al. } \\
2015 \text { [25] }\end{array}$ & $E$ & $8.8 \mathrm{kPa}$ & $88.9 / 91.9$ & 0.94 & NA & NA/NA & NA & NA & NA/NA & NA \\
\hline
\end{tabular}

Note: SWV, shear wave velocity; E, Young's modulus.

specificity of $\mathrm{F} \geq 3$ and sensitivity of $\mathrm{F} \geq 4$ were analyzed under the fixed-effects model, while specificity of $F \geq 2$, sensitivity of $\mathrm{F} \geq 3$ and specificity of $\mathrm{F} \geq 4$ were analyzed under the randomeffects model. According to Deeks funnel plot asymmetry test, no publication bias was detected for the analysis of $F \geq 2, F \geq 3$ and $F \geq 4$ ( $P=0.924,0.494$ and 0.343) (Figure 4).

\section{Fagan plot analysis}

The Fagan plot demonstrated that when the pre-test probabilities were $25 \%$ or $50 \%$ or $75 \%$, the positive post-probabilities of significant fibrosis $(\mathrm{F} \geq 2)$ were $60 \%, 82 \%$ and $93 \%$, and the negative post-probabilities were $6 \%, 15 \%$ and $35 \%$, respectively (Figure 5). For $\mathrm{F} \geq 3$, when the pre-test probabilities were $25 \%$ or $50 \%$ or $75 \%$, the positive post-probabilities were $61 \%$, $83 \%$, and $93 \%$, and the negative post-probabilities were $4 \%$, $11 \%$, and $26 \%$, respectively (Figure 5 ). For $\mathrm{F} \geq 4$, when the pretest probabilities was $25 \%$ or $50 \%$ or $75 \%$, the positive postprobabilities were $70 \%, 88 \%$, and $96 \%$, and the negative postprobabilities were $5 \%, 13 \%$, and $31 \%$, respectively (Figure 5).

\section{Discussion}

SWE, a novel ultrasound-based technique, differs from conventional elastography in which the radiation force is produced by ultrasonic beam to induce the mechanical vibrations automatically. The reliability and reproducibility of SWE does not depend on the sonographer's ability to stress or vibrate tissue correctly. Based on the ultrafast sonographic tracking techniques and the Young's modulus formula, the quantitative information could be delivered as an elasticity index expressed in kilopascals, and real-time elastographic color maps can be displayed, showing stiffer tissue in red and softer tissue in blue. Therefore, SWE could quantify tissue stiffness directly and can be considered as a diagnostic tool that might compensate the limitations of RTE, TE and ARFI [30].

In this meta-analysis, we evaluated the performance of SWE for the assessment of liver stiffness. To the best of our knowledge, this is the first meta-analysis on this topic. Through systematic literature search and screening process, 8 studies assessing the performance of SWE in the diagnosis of liver fibrosis satisfied 

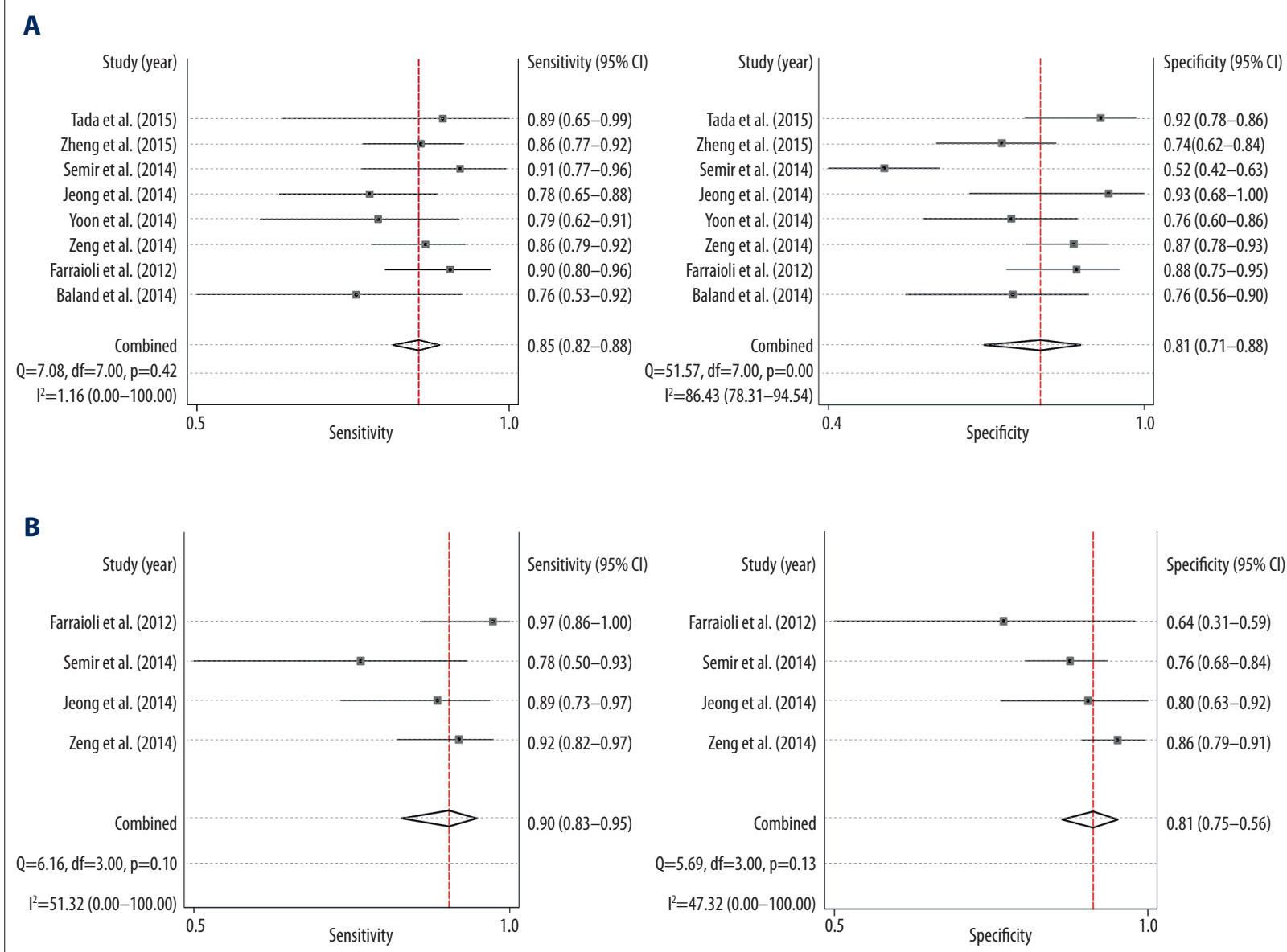

C
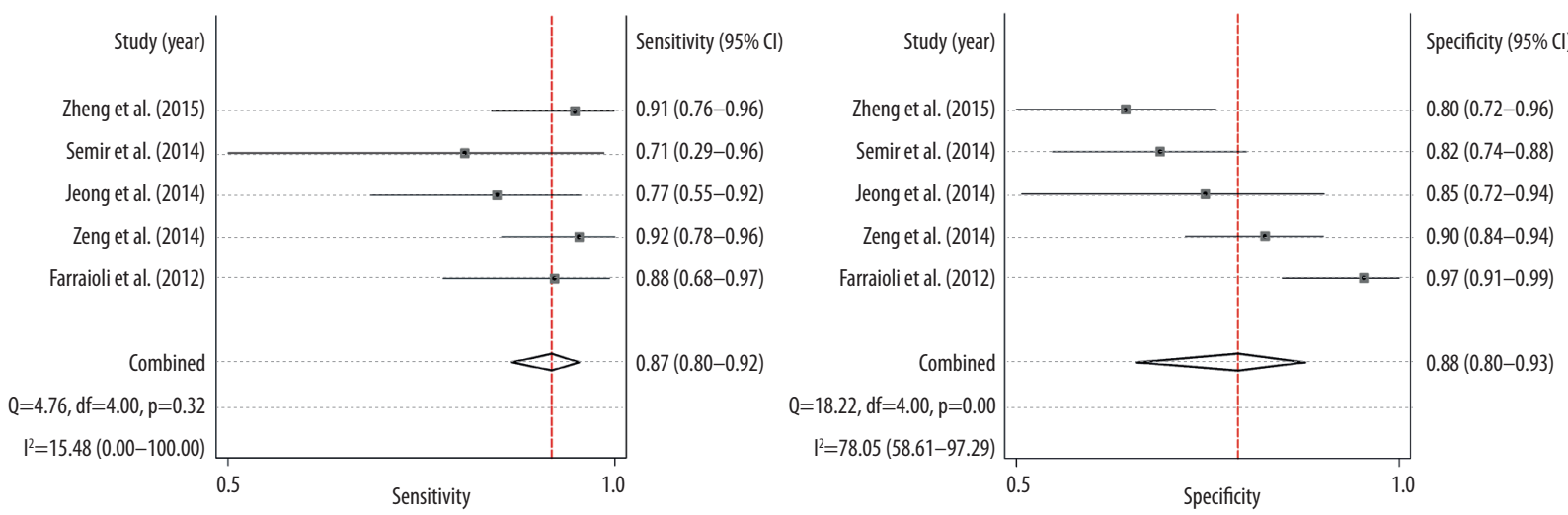

Figure 2. Forest plots of sensitivity and specificity for each study according to (A) $F \geq 2$, (B) $F \geq 3$, and (C) $F \geq 4$.

the inclusion criteria. Sufficient elastographic data including the quantitative stiffness information expressed in $\mathrm{kPa}$ could be extracted from these studies to perform a meta-analysis. The results of our meta-analysis indicate that SWE has high diagnostic accuracy in diagnosing $\mathrm{F} \geq 3$ (sensitivity $90 \%$, specificity $81 \%$ ), $F \geq 4$ (sensitivity $87 \%$, specificity $88 \%$ ) and relatively high accuracy in $\mathrm{F} \geq 2$ (sensitivity $85 \%$, specificity $81 \%$ ). For any cut-off stage of the liver fibrosis, both summary specificity and sensitivity are above $80 \%$. It should be noted that our included studies used patients who underwent liver biopsy with various liver diseases. According to Tsochatzis et al., different etiologies of liver disease might have different stiffness cut-offs 


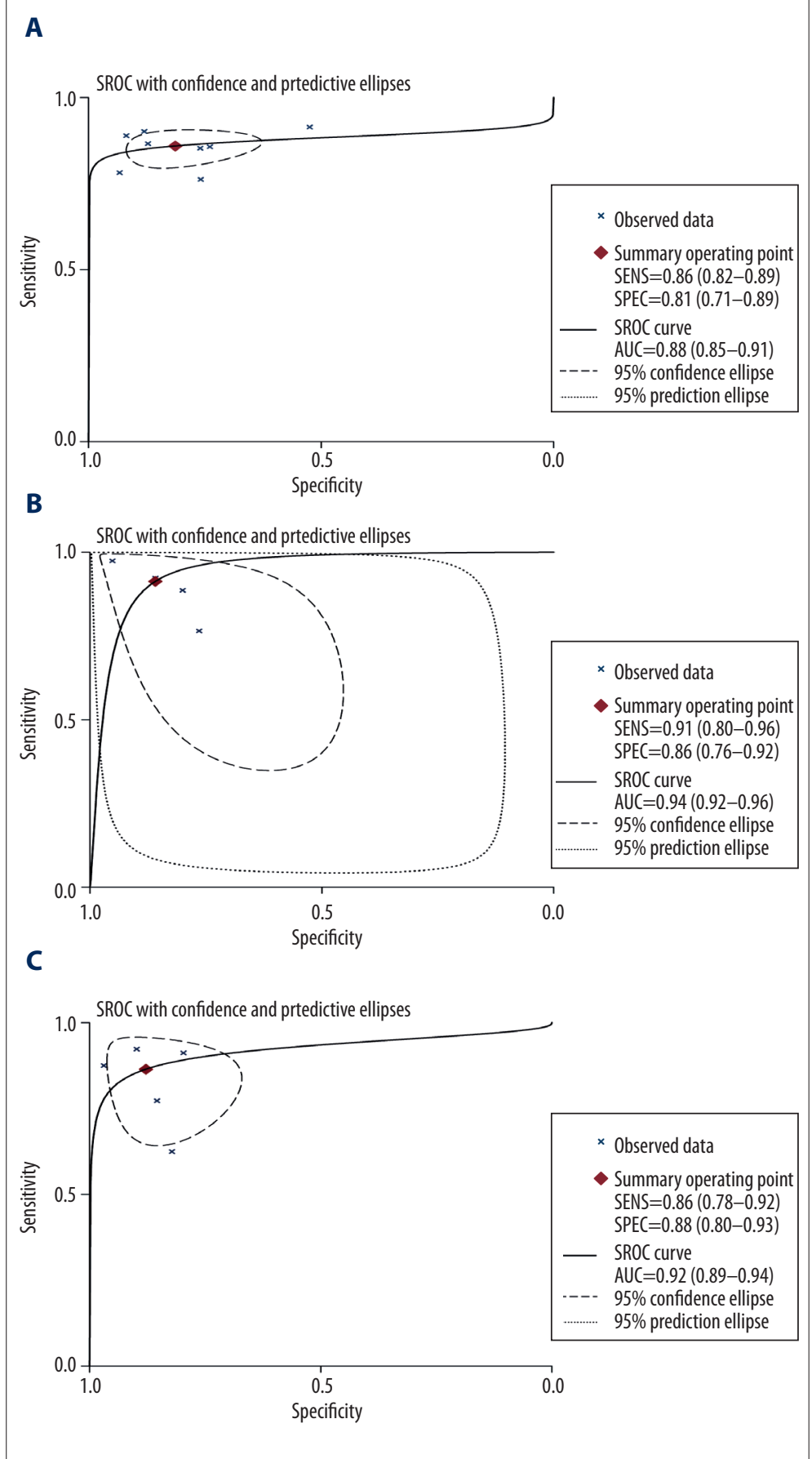

Figure 3. Summary receiver operating characteristic (SROC) curves for estimating the testing accuracy of SWE for (A) $F \geq 2$, (B) $F \geq 3$, and (C) $F \geq 4$. The AUC of SROC was $0.88(0.85-0.91)$, $0.94(0.92-0.96)$, and $0.92(0.89-0.94)$ for $F \geq 2, F \geq 3$, and $F \geq 4$, respectively.

for a given fibrosis stage [31]. Nierhoff et al. conducted a meta-analysis to explore the efficiency of ARFI for the staging of liver fibrosis. They reported that there was a slight trend towards higher diagnostic accuracy in studies with patients only infected with HCV than in studies with patients with different liver diseases. Further subgroup analyses showed a significantly better diagnostic accuracy for the diagnosis of severe fibrosis for the studies without HBV-infected patients than for those including HBV-infected patients. Moreover, given that patients who underwent liver biopsy represent a population biased towards more severe liver diseases, the conclusion from the current study may find more validity among patients with more severe liver diseases than those with mild liver diseases.

The majority of our included studies chose the right lobe as the measurement location. Samir et al. found that the SWE Young modulus of upper right lobe showed the highest correlation with fibrosis stage [14]. When compared with the results 


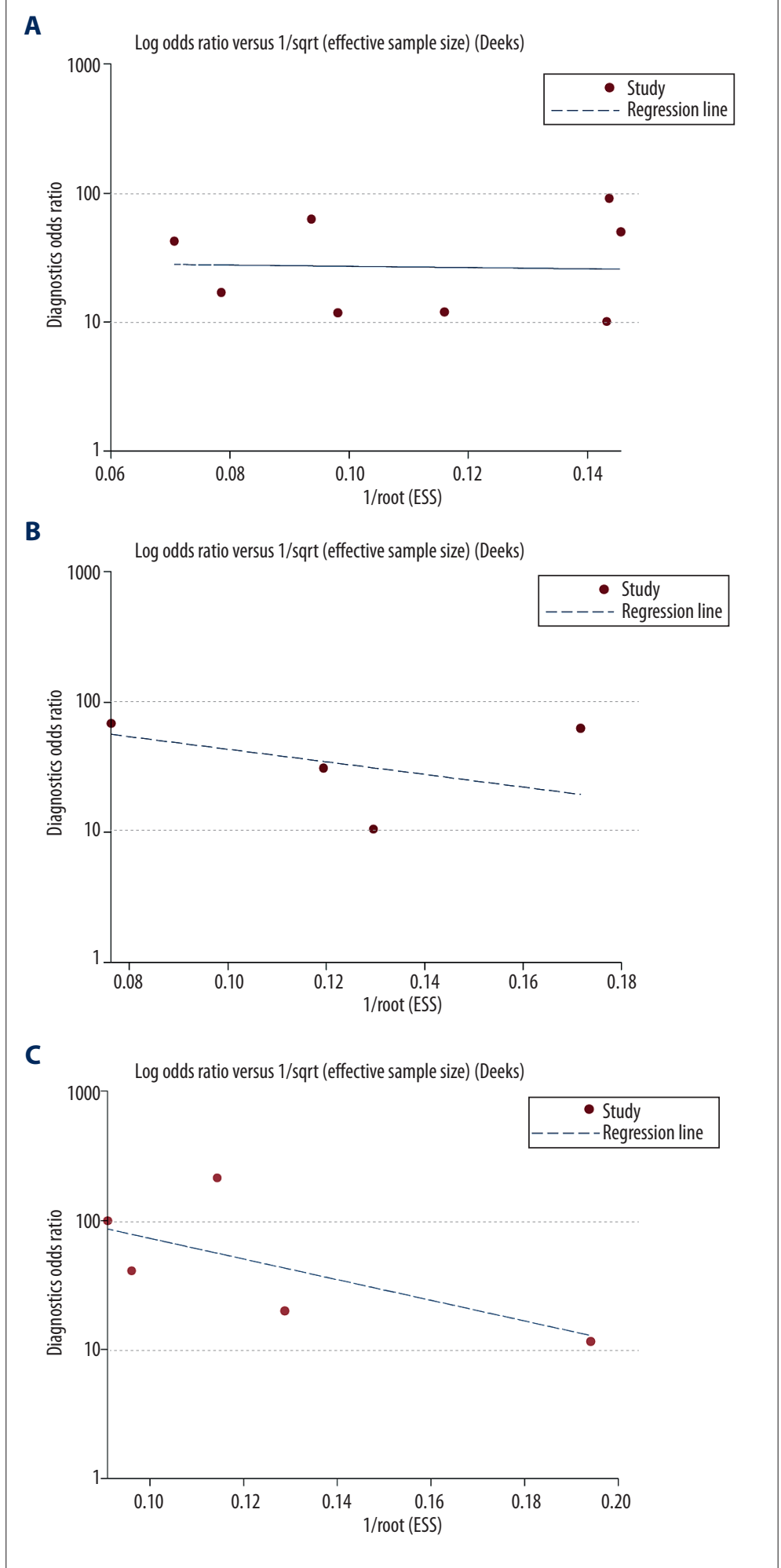

Figure 4. The funnel plot analysis. The analyses showed no potential publication bias for analysis of (A) $F \geq 2$, (B) $F \geq 3$, and (C) $\mathrm{F} \geq 4(P=0.924,0.494,0.343)$.

of meta-analyses on RTE, ARFI, and TE, the pooled sensitivity and specificity of SWE $(87 \%, 88 \%)$ seems to be similar for the diagnosis of cirrhosis $(\mathrm{F} \geq 4)$. The pooled sensitivity and specificity of RTE, ARFI, and TE were $74 \%$ and $84 \%, 87 \%$ and $87 \%$,
$83 \%$ and $89 \%$, respectively. But for the diagnosis of significant fibrosis (F2), the overall accuracy of SWE is higher than that of TE and RTE, and nearly identical with ARFI. For TE and RTE, the summary sensitivities were both reported as $79 \%$ and the

\section{6}

Indexed in: [Current Contents/Clinical Medicine] [SCI Expanded] [ISI Alerting System] [ISI Journals Master List] [Index Medicus/MEDLINE] [EMBASE/Excerpta Medica] [Chemical Abstracts/CAS] [Index Copernicus] 


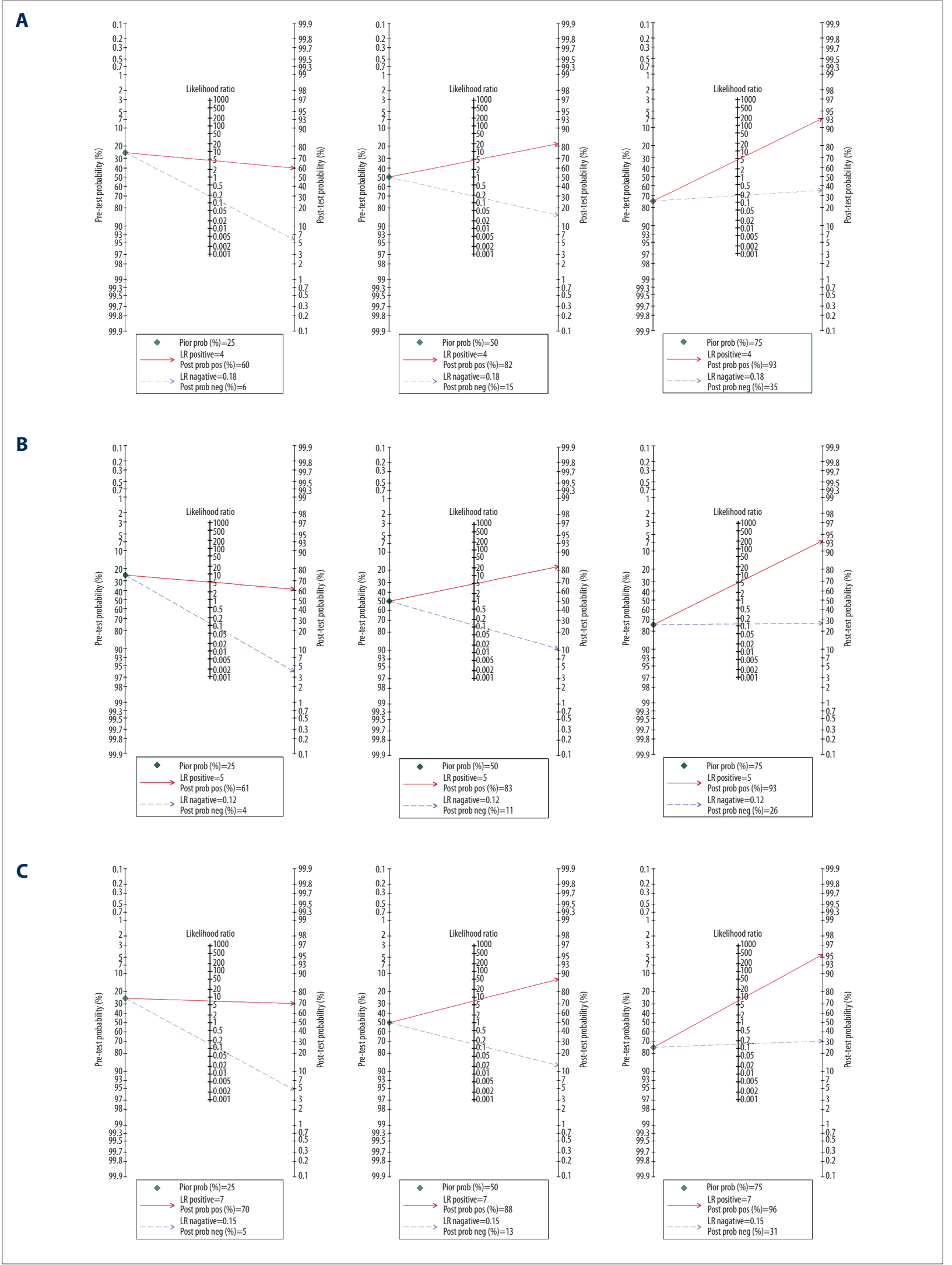

Figure 5. Fagan plot analysis to evaluate the clinical utility of SWE for (A) $F \geq 2$, (B) $F \geq 3$, and (C) $F \geq 4$.

This work is licensed under a Creative Commons Attribution-NonCommercial-NoDerivs 3.0 Unported License

\section{7}

Indexed in: [Current Contents/Clinical Medicine] [SCI Expanded] [ISI Alerting System] [ISI Journals Master List] [Index Medicus/MEDLINE] [EMBASE/Excerpta Medica] [Chemical Abstracts/CAS] [Index Copernicus] 
specificities were $78 \%$ and $76 \%$ respectively, while for ARFI, the pooled sensitivity was reported as $74 \%$ and specificity was $83 \%$ [32-34]. Differentiating significant fibrosis (F2-4) from nonsignificant fibrosis (F0 and F1) has considerable clinical significance for patients with CLDs, especially for the HCV patients because significant fibrosis $(F \geq 2)$ at the time of diagnosis has been shown to correlate with long-term cirrhosis risk $[35,36]$. In this regard, SWE may fill an important void. Furthermore, the elastographic techniques, such as ARFI and TE, have some common limitations. The influence of hepatic inflammation and steatosis on the tissue stiffness is still a matter of debate. According to Rizzo et al., ARFI was not associated with alanine transaminase (ALT) or liver steatosis, while TE was significantly correlated with the ALT value. However, Bota et al. reported that at least 2 stages of liver fibrosis between ARFI results and histologic assessment were associated [37-39]. In the study of Samir et al., the authors rejected the effect of inflammation or steatosis on the fibrosis estimation with the use of SWE [14].

The overall results suggested that SWE has high accuracy in diagnosing $\mathrm{F} \geq 3$ (sensitivity $90 \%$, specificity $81 \%$ ), $\mathrm{F} \geq 4$ (sensitivity $87 \%$, specificity $88 \%$ ), and moderate accuracy in diagnosing $\mathrm{F} \geq 2$ (sensitivity $85 \%$, specificity $81 \%$ ). It is also essential to know that test utility varies with disease perceived risk. Therefore, Fagan plot analysis was performed in this study. In the stage of $\mathrm{F} \geq 2$, when the pre-test probability is $75 \%, 93 \%$ of the patients following "positive" results could be correctly diagnosed. However, when the pre-test probability - is $25 \%$, there is only $60 \%$ probability of correctly diagnosing $\mathrm{F} \geq 2$ with a "positive" result. Similarly, for the stage of $F \geq 3$, when the pre-test probability changes from $75 \%$ to $25 \%$, the post-test probability accordingly decreases from $93 \%$ to $61 \%$. Finally,

\section{References:}

1. Cho SW, Cheong JY: [Clinical application of non-invasive diagnosis for hepatic fibrosis]. Korean J Hepatol, 2007; 13(2): 129-37 [in Korean]

2. Mohd Hanafiah K, Groeger J, Flaxman AD, Wiersma ST: Global epidemiology of hepatitis $C$ virus infection: New estimates of age - specific antibody to HCV seroprevalence. Hepatology, 2013; 57(4): 1333-42

3. Smith JO, Sterling RK: Systematic review: non-invasive methods of fibrosis analysis in chronic hepatitis C. Aliment Pharmacol Ther, 2009; 30(6) 557-76

4. Dienstag JL: The role of liver biopsy in chronic hepatitis C. Hepatology, 2002; 36(5 Suppl.1): S152-60

5. Markiewicz-Kijewska M, Kaliciński $P$, Kluge $P$ et al: Immunological factors and liver fibrosis in pediatric liver transplant recipients. Ann Transplant, 2015; 20: 279-84

6. Bedossa P, Dargere D, Paradis V: Sampling variability of liver fibrosis in chronic hepatitis C. Hepatology, 2003; 38(6): 1449-57

7. Cholongitas $\mathrm{E}$, Senzolo $\mathrm{M}$, Standish $\mathrm{R}$ et al: A systematic review of the quality of liver biopsy specimens. Am J Clin Pathol, 2006; 125(5): 710-21

8. Ratziu V, Charlotte F, Heurtier A et al: Sampling variability of liver biopsy in nonalcoholic fatty liver disease. Gastroenterology, 2005; 128(7): 1898-906

9. Moreno-Otero R, Trapero-Marugan M, Mendoza J: Liver fibrosis assessment by transient elastography in hepatitis $C$ patients with normal alanine aminotransferase. Gut, 2006; 55(7): 1055-56 for $\mathrm{F} \geq 4$, the post-test probability decreases from $96 \%$ to $70 \%$. This analysis indicates that for the staging of liver fibrosis in the low-risk population, SWE still lack appropriate accuracy.

Our study has several limitations. Firstly, we only identify 8 eligible studies that met the inclusion criteria. This may be due to the fact that SWE is still a new technique and largescale studies are required to validate the clinical use of SWE in staging of liver fibrosis. Furthermore, we could not perform subgroup analyses for various liver diseases such as HCV because of the limited number of studies. In addition, our results were generated from different etiological groups within the same analysis. It is known that the relationship between the progression of liver fibrosis and the liver elasticity varies depending on the underlying liver disease. Therefore, in future studies we encourage the researchers to be more rigorous in patient selection.

\section{Conclusions}

Our meta-analysis demonstrates that for the staging of liver fibrosis, the overall accuracy of SWE is good. Compared with the results of meta-analyses on RTE, TE, and ARFI, the performance of SWE seems to be nearly identical for the evaluation of cirrhosis. For the evaluation of significant liver fibrosis $(F \geq 2)$, the overall accuracy of SWE seems to be similar to ARFI, but higher than RTE and TE. However, the conclusion is made just from the data described in this article and some meta-analyses on other elastographic techniques. Large-scale, well-designed, and multi-center studies are needed to validate the conclusion and further evaluate the potential of SWE.

10. Ochi H, Hirooka M, Koizumi Y et al: Real-time tissue elastography for evaluation of hepatic fibrosis and portal hypertension in nonalcoholic fatty liver diseases. Hepatology, 2012; 56(4): 1271-78

11. Haque $M$, Robinson C, Owen $D$ et al: Comparison of acoustic radiation force impulse imaging (ARFI) to liver biopsy histologic scores in the evaluation of chronic liver disease: A pilot study. Ann Hepatol, 2010; 9(3): 289-93

12. Poynard T, Munteanu M, Luckina E et al: Liver fibrosis evaluation using real-time shear wave elastography: applicability and diagnostic performance using methods without a gold standard. J Hepatol, 2013; 58(5): 928-35

13. Tatar IG, Ergun O, Kurt A et al: The role of elastosonography in the differentiation of parotid gland lesions: Report of three cases and review of the literature. Pol J Radiol, 2014; 79: 398-401

14. Samir AE, Dhyani M, Vij A et al: Shear-wave elastography for the estimation of liver fibrosis in chronic liver disease: Determining accuracy and ideal site for measurement. Radiology, 2015; 274(3): 888-96

15. Jeong JY, Kim TY, Sohn JH et al: Real time shear wave elastography in chronic liver diseases: Accuracy for predicting liver fibrosis, in comparison with serum markers. World J Gastroenterol, 2014; 20(38): 13920-29

16. Friedrich-Rust $M$, Ong MF, Martens $S$ et al: Performance of transient elastography for the staging of liver fibrosis: a meta-analysis. Gastroenterology, 2008; 134(4): 960-74

17. Friedrich-Rust $M$, Nierhoff J, Lupsor $M$ et al: Performance of acoustic radiation force impulse imaging for the staging of liver fibrosis: A pooled meta-analysis. J Viral Hepat, 2012; 19(2): e212-19 
18. Hong H, Li J, Jin $\mathrm{Y}$ et al: Performance of real-time elastography for the staging of hepatic fibrosis: a meta-analysis. PloS One, 2014; 9(12): e115702

19. Ferraioli G, Tinelli C, Dal Bello B et al: Accuracy of real-time shear wave elastography for assessing liver fibrosis in chronic hepatitis C: a pilot study. Hepatology, 2012; 56(6): 2125-33

20. Zeng J, Liu GJ, Huang ZP et al: Diagnostic accuracy of two-dimensional shear wave elastography for the non-invasive staging of hepatic fibrosis in chronic hepatitis B: a cohort study with internal validation. Eur Radiol, 2014; 24(10): 2572-81

21. Yoon JH, Lee JM, Joo I et al: Hepatic fibrosis: prospective comparison of MR elastography and US shear-wave elastography for evaluation. Radiology, 2014; 273(3): 772-82

22. Beland MD, Brown SF, Machan JT et al: A pilot study estimating liver fibrosis with ultrasound shear-wave elastography: does the cause of liver disease or location of measurement affect performance? Am J Roentgenol, 2014; 203(3): W267-73

23. Tutar O, Beser OF, Adaletli I et al: Shear wave elastography in the evaluation of liver fibrosis in children. J Pediatr Gastroenterol Nutr, 2014; 58(6): 750-55

24. Yoon JH, Lee JM, Woo HS et al: Staging of hepatic fibrosis: comparison of magnetic resonance elastography and shear wave elastography in the same individuals. Korean J Radiol, 2013; 14(2): 202-12

25. Huang ZP, Zhang XL, Zeng J et al: Study of detection times for liver stiffness evaluation by shear wave elastography. World J Gastroenterol, 2014; 20(28): 9578-84

26. Zheng J, Guo H, Zeng J et al: Two-dimensional shear-wave elastography and conventional US: The optimal evaluation of liver fibrosis and cirrhosis. Radiology, 2015; 275(1): 290-300

27. Tada T, Kumada T, Toyoda $\mathrm{H}$ et al: Utility of real-time shear wave elastography for assessing liver fibrosis in patients with chronic hepatitis $\mathrm{C}$ infection without cirrhosis: Comparison of liver fibrosis indices. Hepatol Res, 2015; 45(10): E122-29

28. Sporea I, Bota S, Gradinaru-Tascau O et al: Which are the cut-off values of 2D-Shear Wave Elastography (2D-SWE) liver stiffness measurements predicting different stages of liver fibrosis, considering Transient Elastography (TE) as the reference method? Eur J Radiol, 2014; 83(3): e118-22
29. Hellmich $M$, Lehmacher W: A ruler for interpreting diagnostic test results. Methods Inf Med, 2005; 44(1): 124-26

30. Ferraioli G, Tinelli C, Malfitano A et al: Performance of real-time strain elastography, transient elastography, and aspartate-to-platelet ratio index in the assessment of fibrosis in chronic hepatitis C. Am J Roentgenol, 2012; 199(1): 19-25

31. Tsochatzis E, Gurusamy K, Ntaoula S et al: Elastography for the diagnosis of severity of fibrosis in chronic liver disease: a meta-analysis of diagnostic accuracy. J Hepatol, 2011; 54(4): 650-59

32. Tsochatzis EA, Gurusamy KS, Ntaoula $S$ et al: Elastography for the diagnosis of severity of fibrosis in chronic liver disease: a meta-analysis of diag nostic accuracy. J Hepatol, 2011; 54(4): 650-59

33. Bota S, Herkner H, Sporea I et al: Meta-analysis: ARFI elastography versus transient elastography for the evaluation of liver fibrosis. Liver Int, 2013 33(8): 1138-47

34. Kobayashi K, Nakao H, Nishiyama T et al: Diagnostic accuracy of real-time tissue elastography for the staging of liver fibrosis: a meta-analysis. Eur Radiol, 2015; 25(1): 230-38

35. Kato Y, Nakata K, Nagataki S et al: Risk of hepatocellular carcinoma in patients with cirrhosis in Japan. Analysis of infectious hepatitis viruses. Cancer 1994; 74(8): 2234-38

36. Takano S, Yokosuka O, Imazeki F et al: Incidence of hepatocellular carcinoma in chronic hepatitis B and C: a prospective study of 251 patients. Hepatology, 1995; 21(3): 650-55

37. Rifai K, Cornberg J, Mederacke I et al: Clinical feasibility of liver elastography by acoustic radiation force impulse imaging (ARFI). Digest Liver Dis, 2011; 43(6): 491-97

38. Bota S, Sporea I, Sirli R et al: Factors which influence the accuracy of acous tic radiation force impulse (ARFI) elastography for the diagnosis of liver fibrosis in patients with chronic hepatitis C. Ultrasound Med Biol, 2013; 39(3): 407-12

39. Rizzo L, Calvaruso V, Cacopardo B et al: Comparison of transient elastography and acoustic radiation force impulse for non-invasive staging of liver fibrosis in patients with chronic hepatitis C. Am J Gastroenterol, 2011; 106(12): 2112-20 